\title{
ISCHEMIC AND REPERFUSION INJURY OF CYANOTIC MYOCARDIUM IN CHRONIC HYPOXIC RAT MODEL: CHANGES IN CYANOTIC MYOCARDIAL ANTIOXIDANT SYSTEM
}

Koji Nakanishi, MD

Masahiro Inoue, MD

Eiji Sugawara, MD

Shunji Sano, MD
Objective: The objective was to evaluate the effect of left ventricular function on cyanotic myocardium after ischemia-reperfusion and to determine the effect of cyanosis on the myocardial antioxidant system. Methods: Cyanotic hearts (cyanotic group) were obtained from rats housed in a hypoxic chamber (10\% oxygen) for 2 weeks and control hearts (control group) from rats maintained in ambient air. Isolated, crystalloid perfused working hearts were subjected to 15 minutes of global normothermic ischemia and 20 minutes of reperfusion, and functional recovery was evaluated in the two groups. Myocardial superoxide dismutase, glutathione peroxidase, glutathione reductase activity, and reduced glutathione content were measured separately in the cytoplasm and mitochondria at the end of the preischemic, ischemic, and reperfusion periods. Results: Mean cardiac output/left ventricular weight was not significantly different between the two groups. Percent recovery of cardiac output was significantly lower in the cyanotic group than in the controi group $(56.1 \% \pm 5.7 \%$ vs $73.0 \% \pm 3.1 \%, p=0.001)$. Mitochondrial superoxide dismutase, mitochondrial and cytosolic glutathione reductase activity, and cytosolic reduced glutathione were significantly lower in the cyanotic group than in the control group at end-ischemia (superoxide dismutase, $3.7 \pm 1.3$ vs $5.9 \pm 1.5$ units $/ \mathrm{mg}$ protein, $p=0.012$; mitochondrial glutathione reductase, $43.7 \pm 14.0 \mathrm{vs} 71.0 \pm 30.3$ munits $/ \mathrm{mg}$ protein, $p=0.039$; cytosolic glutathione reductase, $13.7 \pm 2.0$ vs $23.2 \pm 4.2$ munits/mg protein, $p<0.001$; and reduced glutathione, $0.69 \pm 0.10 \mathrm{vs}$ $0.91 \pm 0.24 \mu \mathrm{g} / \mathrm{mg}$ protein, $p=0.037$ ). Conclusions: Cyanosis impairs postischemic functional recovery and depresses myocardial antioxidant reserve during ischemia. Reduced antioxidant reserve at end-ischemia may result in impaired postischemic functional recovery of cyanotic myocardium. (J Thorac Cardiovasc Surg 1997;114:1088-96)
$\mathrm{H}^{\mathrm{s}}$ ospital mortality rate of repair of cyanotic congenital heart defects has decreased dramatically with recent advances in myocardial protection, surgical techniques, and postoperative intensive care. ${ }^{1}$ Acute cardiac failure during the postoperative period, however, remains one of the most important causes of hospital death in these patients. ${ }^{1}$ Previous experimental studies have shown that chronic cya-

From the Department of Cardiovascular Surgery, Okayama University Medical School, Okayama, Japan.

Received for publication March 11, 1997; revisions requested May 15, 1997; revisions received June 19, 1997; accepted for publication June 25, 1997.

Address for reprints: Koji Nakanishi, MD, Department of Cardiovascular Surgery, Okayama University Medical School, 2-5-1 Shikata-cho, Okayama 700, Japan.

Copyright (C 1997 by Mosby-Year Book, Inc.

$0022-5223 / 97 \$ 5.00+0 \quad \mathbf{1 2} / \mathbf{1} / \mathbf{8 4 4 2 1}$ nosis itself is an important factor in acute cardiac failure. ${ }^{2}$ However, why chronic cyanosis impairs postischemic cardiac function has not been adequately evaluated.

Activity of myocardial antioxidant enzymes and concentrations of antioxidants have been found to be correlated with recovery of structure and function after reoxygenation. ${ }^{3}$ In many previous studies, acute hypoxia has been shown to depress myocardial antioxidants, ${ }^{3}$ whereas myocardial antioxidants during chronic hypoxia have not been adequately studied. ${ }^{4}$ The purpose of our study was to evaluate the effect of left ventricular (LV) function on cyanotic myocardium after ischemia-reperfusion, to determine the effect of cyanosis on the myocardial antioxidant system, and to elucidate the effect of ischemia and reperfusion on the cyanotic myocardial antioxidant system. 

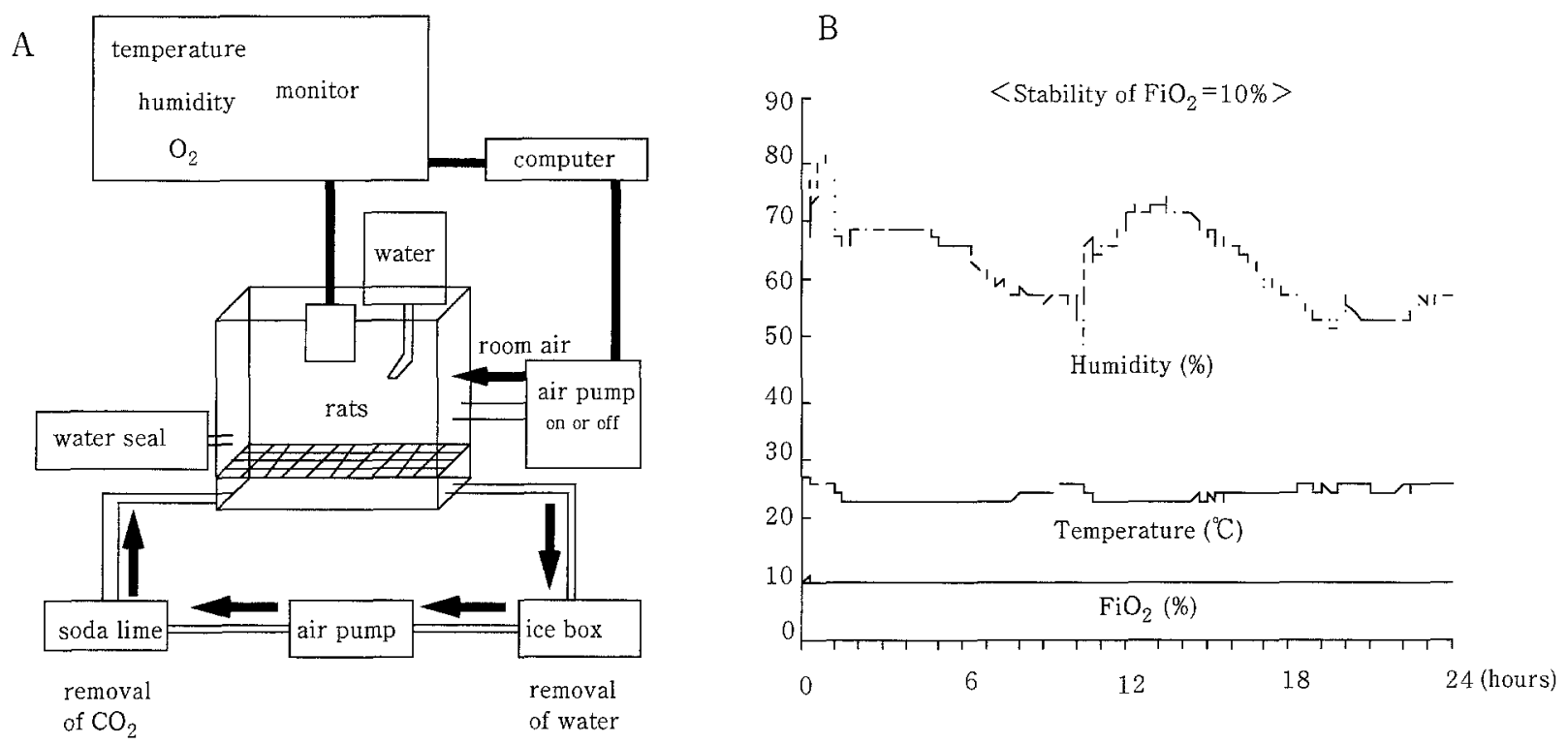

Fig. 1. A, Schematic representation of normobaric hypoxic chamber. (Direction of gas flow is shown by arrows.) B, Serial changes of humidity, temperature, and inspired oxygen fraction $\mathbf{F i O}_{2}$ ) in the hypoxic chamber. Oxygen concentration within the chamber was maintained within $10 \% \pm 0.1 \%$.

\section{Materials and methods}

Male 8-week-old Wistar rats, weighing 250 to $280 \mathrm{gm}$, were used. They were treated in compliance with the "Principles of Laboratory Animal Care" established by the National Society for Medical Research and the "Guide for the Care and Use of Laboratory Animals" prepared by the Institute of Laboratory Animal Resources and published by the National Institutes of Health (NIH publication No. 86-23, revised 1985). The rats were divided randomly into control and cyanotic (chronically hypoxic) groups. The rats in the cyanotic group were housed in a normobaric, hypoxic chamber (range 10\% \pm $0.1 \%$ oxygen) for 2 weeks, whereas rats in the control group were housed in ambient air for the same period.

A previously described normobaric, hypoxic chamber was modified for use in our study (Fig. $1, A) .^{5}$ The environment within the chamber was continuously monitored with an oxygen analyzer. The oxygen concentration within the chamber was maintained within $10 \% \pm 0.1 \%$ by means of an air pump regulated by a programmed computer connected to an oxygen analyzer. Carbon dioxide was removed by soda lime granules and excess humidity by cooling of the recirculation circuit. Air was sampled periodically for analysis, and inspired carbon dioxide fraction within the chamber was maintained at less than $0.4 \%$ at all times. Humidity within the hypoxic chamber was maintained at less than $70 \%$ and temperature between $22^{\circ}$ and $26^{\circ} \mathrm{C}$ (Fig. 1, B). All the control and cyanotic rats were kept in the same room under the same light-dark cycle. Rat chow and tap water were provided ad libitum.

After the hypoxic or normoxic exposure period, the rats were anesthetized with diethyl ether. Arterial blood samples were obtained from the exposed abdominal aorta in a hypoxic or normoxic environment. After thoracotomy, the heart was excised and immersed in cold heparinized saline solution $\left(4^{\circ} \mathrm{C}\right)$. Arterial oxygen tension and oxygen saturation were measured by a blood gas analyzer. Hematocrit value was also determined. Right ventricular free wall (RV) and LV wall and septum were weighed separately. The ratios of $\mathrm{RV} / \mathrm{LV}, \mathrm{RV}$ (grams)/body weight (kilograms), LV/body weight, and total wet heart weight/body weight were calculated. At least five hearts were used in each experiment.

The isolated perfused working rat heart apparatus described by Hearse, Stewart, and Braimbridge ${ }^{6}$ was used for our study with some modifications. Rats were anesthetized with diethyl ether and 300 units of heparin was injected into the exposed femoral vein. Hearts were rapidly excised 1 minute later and immersed in cold perfusion medium $\left(4^{\circ} \mathrm{C}\right)$. Chronically cyanotic rats were anesthetized and their hearts were excised in a hypoxic environment.

The experimental protocol is outlined in Fig. 2. Each heart was cannulated via the aorta, and Langendorff perfusion was initiated at a pressure of $80 \mathrm{~cm} \mathrm{H}_{2} \mathrm{O}$. The perfusate was a modified Krebs-Henseleit bicarbonate buffer solution, consisting of $\mathrm{NaCl} 118 \mathrm{mmol} / \mathrm{L}, \mathrm{NaHCO}_{3}$ $25 \mathrm{mmol} / \mathrm{L}, \mathrm{KCl} 4.7 \mathrm{mmol} / \mathrm{L}, \mathrm{CaCl}_{2} 2.5 \mathrm{mmol} / \mathrm{L}, \mathrm{MgSO}_{4}$ $1.2 \mathrm{mmol} / \mathrm{L}, \mathrm{KH}_{2} \mathrm{PO}_{4} 1.2 \mathrm{mmol} / \mathrm{L}$, and glucose $11 \mathrm{mmol} / \mathrm{L}$, which was bubbled with $95 \%$ oxygen and $5 \%$ carbon dioxide gas. The temperature of the perfusate was continuously monitored and maintained at $37.0^{\circ} \pm 0.1^{\circ} \mathrm{C}$. The perfusate was filtered through $0.45 \mu \mathrm{m}$ pores. During 10 minutes of Langendorff perfusion, the pulmonary artery was incised to permit drainage of coronary sinus effluent, and left atrial cannulation was performed. The preparation then was converted to the working heart mode for a 


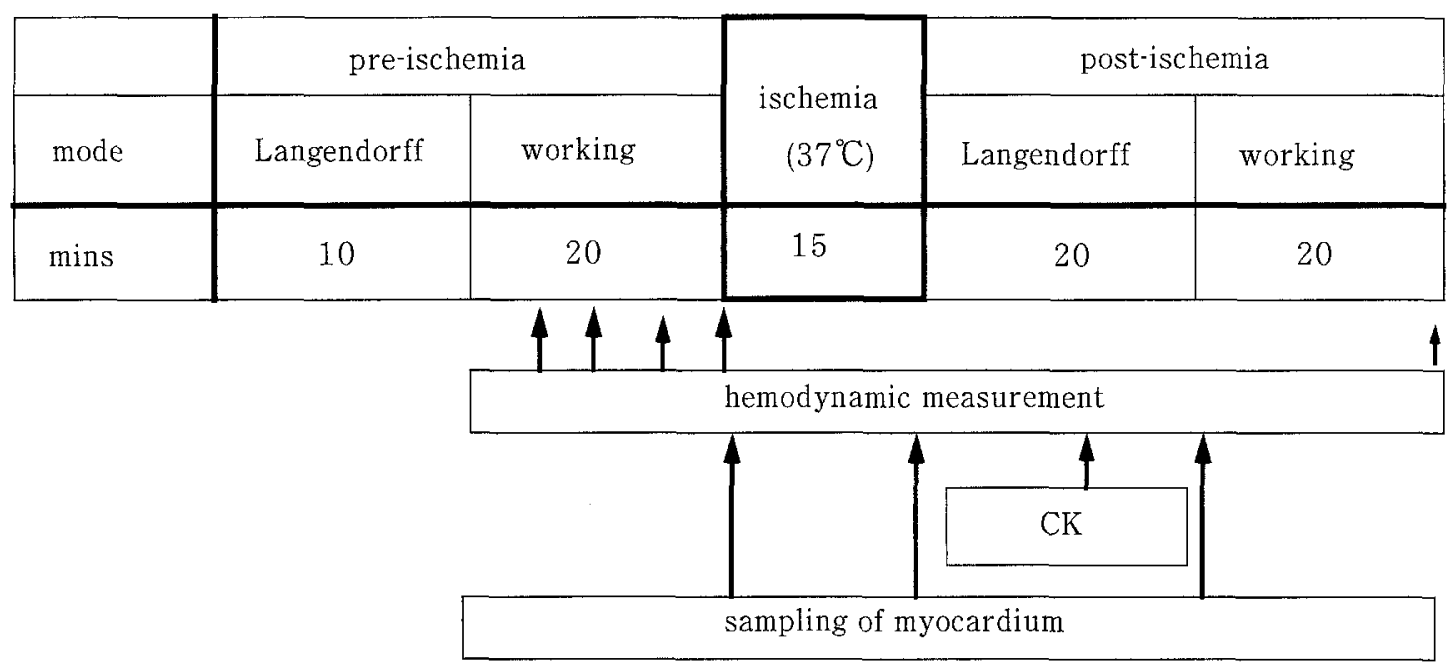

Fig. 2. Experimental protocol. Global normothermic ischemia for 15 minutes. Parallel groups of hearts were sampled for myocardial antioxidants at the end of the preischemic, ischemic, and reperfusion periods. $C K$, Creatine kinase.

20-minute period. In the working mode, the hearts were perfused via the left atrium at an atrial perfusion pressure of $20 \mathrm{~cm} \mathrm{H} \mathrm{H}_{2} \mathrm{O}$. The ventricle was spontaneously ejected into a compliance chamber with a $2.5 \mathrm{ml}$ air cap and against hydrostatic pressure of $100 \mathrm{~cm} \mathrm{H}_{2} \mathrm{O}$. The aortic flow was recirculated but not the coronary flow. Aortic pressure was measured by a pressure transducer connected to a side arm of the aortic cannula. Aortic flow was measured in the aortic column by an electromagnetic flowmeter (MFV-1100, Nihon Koden Co.), and coronary flow was measured by timed volumetric collection from the right side of the heart. Cardiac output was calculated by adding the aortic and coronary flows. The heart rate was obtained from the aortic pressure tracing. All hemodynamic parameters in the two groups were measured in the working mode without ischemia until 60 minutes. They were calculated as percentages of their respective 10 -minutes values. The measured preischemic hemodynamic parameters were coronary flow (milliliters per minute)/total wet heart weight (grams), aortic flow (milliliters per minute)/LV weight (grams), and cardiac output (milliliters per minute)/LV weight (grams). Global normothermic ischemia was induced for 15 minutes by clamping the aortic and atrial cannulas. Temperature in the sealed heart chamber was monitored continuously during ischemia and maintained between $36.5^{\circ}$ and $37.0^{\circ} \mathrm{C}$. The heart was reperfused with buffer solution through the aortic root for 20 minutes in the nonworking mode. During this mode, coronary effluent was collected in an ice-cooled bath, and the total creatine kinase leakage was measured. The activated backward reaction with $N$-acetylcysteine as activator was used for creatine kinase determinations. Total creatine kinase leakage was expressed as international units per 20 minutes per gram dry weight. The heart was then converted to the working mode and postischemic measurements were made after 20 minutes. Cardiac output, aortic flow, coronary flow, and heart rate were calculated as percentages of their respective preischemic values. At the end of this experiment, the hearts were removed from the apparatus, heated to $90^{\circ} \mathrm{C}$ for 7 days, and reweighed to determine the dry weight.

At the end of preischemic, ischemic, and reperfusion periods, parallel groups of hearts were assayed for myocardial superoxide dismutase (SOD), glutathione peroxidase (GPX), glutathione reductase (GR), and reduced glutathione (GSH). The hearts were frozen with liquid nitrogen and stored at $-70^{\circ} \mathrm{C}$ until use.

The heart was rejected when the heart rate was less than 300 beats/min or when aortic flow was less than 70 $\mathrm{ml} / \mathrm{min}$ in the control group or $50 \mathrm{ml} / \mathrm{min}$ in the cyanotic group, indicating serious iatrogenic injury during the preparation.

SOD activity was measured by electron spin resonance spectrometry as reported by Mitsuta and colleagues. ${ }^{7}$ The results were expressed as units per milligram of protein. GPX activity was assayed by the method of continuous monitoring of oxidized glutathione formation, as described by Sugiyama and colleagues. ${ }^{8}$ GR was determined by the method of Carlberg and Mannervik. ${ }^{9}$ The activity of GPX or GR that catalyzes the oxidation of $1 \mu \mathrm{mol}$ of reduced nicotinamide adenine dinucleotide phosphate per minute is defined as 1 unit. The results were expressed as milliunits per milligram protein. GSH was determined by the method of Hissin and Hilf ${ }^{10}$ by means of a fluorometric assay. The results were expressed as micrograms per milligram protein. Mitochondrial and cytosolic preparations were performed according to the method of Ambrosio and associates. ${ }^{11}$ Protein in mitochondrial and cytosolic fractions was precipitated with sulfosalicylic acid.

Statistical analysis. At least five hearts were used in each group. All data were expressed as mean \pm standard deviation of the mean. The activities of antioxidant enzymes and the concentration of GSH were compared by two-way analysis of variance for multiple comparisons. 
Table I. Final body weight, arterial oxygen tension, oxygen saturation, hematocrit value, and wet heart weight

\begin{tabular}{|c|c|c|c|c|c|c|c|}
\hline & $B W(g m)$ & $\begin{array}{c}\mathrm{PaO}_{2} \\
(\mathrm{~mm} \mathrm{Hg})\end{array}$ & $\mathrm{O}_{2}$ sat $(\%)$ & Htc (\%) & $R V / L V$ & $\begin{array}{l}R V / B W \\
(g m / k g)\end{array}$ & $\begin{array}{l}L V / B W \\
(\mathrm{gm} / \mathrm{kg})\end{array}$ \\
\hline Control $(n=5)$ & $339 \pm 3$ & $111.1 \pm 2.7$ & $98.4 \pm 0.1$ & $45.4 \pm 0.7$ & $0.22 \pm 0.01$ & $0.47 \pm 0.02$ & $2.15 \pm 0.02$ \\
\hline Cyanosis $(n=5)$ & $295 \pm 4^{*}$ & $42.9 \pm 2.4^{*}$ & $82.1 \pm 3.1^{*}$ & $62.9 \pm 1.2^{*}$ & $0.39 \pm 0.02^{*}$ & $0.86 \pm 0.05^{*}$ & $2.19 \pm 0.05$ \\
\hline
\end{tabular}

Values are means \pm standard deviation. $\mathrm{BW}$, Final body weight; $\mathrm{PaO}_{2}$, arterial oxygen tension; $\mathrm{O}_{2}$ sat, oxygen saturation; $\mathrm{Htc}$, hematocrit value; $\mathrm{RV}$, right ventricle wet weight; $L V$, left ventricle wet weight.

${ }^{*} p<0.05$ when compared with matched control group.

Table II. Preischemic hemodynamic parameters

\begin{tabular}{lccccc}
\hline & $\begin{array}{c}H R \\
(\text { beats } / \mathrm{min})\end{array}$ & $\begin{array}{c}A P(S) \\
(\mathrm{mm} \mathrm{Hg})\end{array}$ & $\begin{array}{c}\text { CF/total } \\
(\mathrm{ml} / \mathrm{gm} / \mathrm{min})\end{array}$ & $\begin{array}{c}\text { AF/LV } \\
(\mathrm{ml} / \mathrm{gm} / \mathrm{min})\end{array}$ & $\begin{array}{c}C O / L V \\
(\mathrm{ml} / \mathrm{gm} / \mathrm{min})\end{array}$ \\
\hline Control $(n=6)$ & $343 \pm 7$ & $111 \pm 2$ & $24.7 \pm 0.8$ & $107.2 \pm 3.5$ & $137.8 \pm 4.0$ \\
Cyanosis $(n=6)$ & $347 \pm 7$ & $118 \pm 1^{*}$ & $32.2 \pm 1.1^{*}$ & $93.8 \pm 4.9^{*}$ & $138.7 \pm 4.3$
\end{tabular}

In isolated crystalloid perfused working rat hearts, preischemic cardiac output (ml)/LV weight (gm) in cyanotic group was not significantly different from that in control group. Values are means \pm standard deviation. $H R$, Heart rate; $A P(S)$, systolic aortic pressure; $C F$, coronary flow; $A F$, aortic flow; $C O$, cardiac output; total, total heart wet weight; $L V$, left ventricle wet weight.

${ }^{*} p<0.05$ when compared with matched control group.

Other parameters were compared within groups by a nonpaired $t$ analysis. A $p$ value of less than 0.05 was regarded to be statistically significant.

\section{Results}

Growth was disturbed in the cyanotic group when compared with the control group. Arterial oxygen tension and oxygen saturation were $42.9 \pm 5.4 \mathrm{~mm}$ $\mathrm{Hg}$ and $82.1 \pm 6.9 \%$, respectively, in the cyanotic group. The cyanotic group showed a significant increase in hematocrit value $(62.9 \% \pm 2.7 \%)$ when compared with the control group. The ratios RV weight/body weight and RV/LV were significantly higher in the cyanotic group, whereas the ratio LV weight/body weight was not significantly different between the two groups (Table I).

There was no difference in change of all hemodynamic parameters until 60 minutes in the working mode without ischemia between the cyanotic and control groups (cardiac output after 60 minutes, $95.4 \% \pm 1.1 \%$ vs $98.5 \% \pm 3.1 \%, p=0.068$ ). Preischemic hemodynamic data are summarized in Table II. There was no difference in preischemic heart rate between the cyanotic and control groups. Mean aortic pressure was significantly higher in the cyanotic group. As mean LV weight was significantly lower in the cyanotic group, preischemic aortic flow and cardiac output were expressed as aortic flow (milliliters per minute)/LV weight (grams) and cardiac output (milliliters per minute)/LV weight (grams). Preischemic coronary flow was expressed as coronary flow (milliliters per minute)/total wet heart weight (grams). Coronary flow/total wet heart weight in the cyanotic group significantly increased, whereas aortic flow/LV weight significantly decreased when compared with the control group. Cardiac output/LV weight was not significantly different between the two groups.

Postischemic recovery of LV function was impaired in the cyanotic hearts compared with the control hearts (Table III). Percent recovery of aortic flow was $46.7 \% \pm 11.1 \%$ in the cyanotic group compared with $70.8 \% \pm 3.2 \%$ in the control group $(p=0.002)$. The percent recovery of cardiac output was $56.1 \% \pm 5.7 \%$ in the cyanotic group compared with $73.0 \% \pm 3.1 \%(p=0.001)$ in the control group. There were no differences in percent recovery of heart rate, peak aortic pressure, or coronary flow between the two groups. Total creatine kinase leakage tended to be greater in the cyanotic group than in the control group $(42.7 \pm 17.5 \mathrm{IU} / 20 \mathrm{~min}$ vs $25.1 \pm 16.1 \mathrm{IU} / 20 \mathrm{~min} / \mathrm{gm}$ dry weight).

There was no difference in the preischemic mitochondrial or cytosolic SOD activity between the cyanotic and control groups (Fig. 3, A). Mitochondrial SOD was significantly reduced during ischemia in the cyanotic group $(p=0.013)$, whereas it remained unchanged in the control group (Fig. 3, $A$ ). Mitochondrial SOD during ischemia was significantly lower in the cyanotic group $(3.7 \pm 1.3$ units $/ \mathrm{mg}$ vs $5.9 \pm 1.5$ units $/ \mathrm{mg}$ protein, $p=0.012$ ) (Fig. 3, A). The activity of cytosolic SOD was not changed during ischemia and reperfusion in either group.

Mitochondrial and cytosolic GSH did not change during ischemia or reperfusion in the cyanotic 
Table III. Percent recovery of hemodynamic parameters and creatine kinase activity in the coronary effluent

\begin{tabular}{lcccccc} 
& & & & \multicolumn{3}{c}{ CK (IU/dry weight } \\
& $H R(\%)$ & $A P(S)(\%)$ & $C F(\%)$ & $A F(\%)$ & $C O(\%)$ & 20 min $)$ \\
\hline Control $(n=6)$ & $96.9 \pm 1.7$ & $94.7 \pm 1.1$ & $81.1 \pm 1.8$ & $70.8 \pm 1.3$ & $73.0 \pm 1.2$ & $25.1 \pm 6.6$ \\
Cyanosis $(n=6)$ & $94.6 \pm 1.6$ & $92.2 \pm 1.3$ & $73.8 \pm 2.8$ & $46.7 \pm 4.5^{*}$ & $56.1 \pm 2.3^{*}$ & $42.7 \pm 7.1$ \\
\hline
\end{tabular}

After global normothermic ischemia for 15 minutes, percent recovery of aortic flow and cardiac output were significantly lower in cyanotic group compared with control group. Values are means \pm standard deviation. $H R$, Heart rate; $A P(S)$, systolic aortic pressure; $C F$, coronary flow; $A F$, aortic flow; $C O$, cardiac output; $C K$, creatine kinase activity. Percent recovery = preischemic parameter/postischemic parameter $\times 100$.

${ }^{*} p<0.01$ when compared with matched control.

group, whereas in the control group mitochondrial GSH was significantly reduced during ischemia and increased during reperfusion (Fig. 3, B). There was no difference in mitochondrial GSH between the two groups at any time, whereas cytosolic GSH was lower in the cyanotic group during preischemia and end-ischemia (preischemia, $0.72 \pm 0.22 \mu \mathrm{g} / \mathrm{mg}$ vs $1.02 \pm 0.29 \mu \mathrm{g} / \mathrm{mg}$ protein, $p=0.035$; end-ischemia, $0.69 \pm 0.10 \mu \mathrm{g} / \mathrm{mg}$ vs $0.91 \pm 0.24 \mu \mathrm{g} / \mathrm{mg}$ protein, $p=$ 0.037) (Fig. 3, B).

Mitochondrial and cytosolic GR did not change during ischemia and reperfusion in the cyanotic group, whereas in the control group cytosolic GR was reduced significantly during reperfusion (Fig. 3, C). There was a significant difference in mitochondrial GR between the cyanotic and control groups at end-ischemia ( $43.7 \pm 14.0$ munits $/ \mathrm{mg}$ vs $71.0 \pm 30.3$ munits/mg protein, $p=0.039$ ). Cytosolic GR was lower in the cyanotic group during preischemia and end-ischemia (preischemia, $15.0 \pm 1.8$ munits $/ \mathrm{mg}$ vs $24.0 \pm 4.5$ munits $/ \mathrm{mg}$ protein, $p<0.001$; endischemia, $13.7 \pm 2.0$ munits $/ \mathrm{mg}$ vs $23.2 \pm 4.2$ munits/mg protein, $p<0.001$ ) (Fig. 3, C). Mitochondrial and cytosolic GPX did not change during ischemia or reperfusion in the cyanotic group, whereas in the control group cytosolic GPX was significantly increased during reperfusion when compared with ischemia (Fig. 3, D). Cytosolic GPX activity was lower in the control group than in the cyanotic group at all times (Fig. $3, D$ ).

\section{Discussion}

The model of chronic hypoxia in our study has not been used to evaluate the effects of ischemia and reperfusion on cyanotic myocardium. Arterial oxygen tension, oxygen saturation, and hematocrit observed experimentally in our rats were similar to those observed clinically in patients with congenital cyanotic heart diseases. ${ }^{12}$ Previous experimental studies used models created by right-to-left shunt to evaluate the effects of ischemia and reperfusion on cyanotic myocardium, ${ }^{2}$ whereas the model of chronic hypoxia was used in our study. Our preparation has two advantages over right-to-left shunting; it does not require any surgical procedure and it can simplify animal models that have equivalent levels of cyanosis.

Preischemic increased coronary flow in chronically hypoxic rats has been attributed to increased vascularity of the heart. ${ }^{13}$ Mean aortic pressure was significantly higher in the cyanotic group. The cause of this result could not be determined, but the pattern of ventricular contraction is different in cyanotic hearts from that in normoxic hearts.

McGrath and Bullard ${ }^{14}$ have reported that chronically hypoxic rat hearts have increased resistance to acute hypoxia, but our results indicate that chronic hypoxia (chronic cyanosis) decreases resistance to ischemia. Reaction of cardiac function to reoxygenation is different after ischemia and acute hypoxia. ${ }^{15}$ The present results support previous experimental studies in models of cyanosis created by right-to-left shunt. ${ }^{2}$ Ihnken and colleagues, ${ }^{16}$ in their recent extensive and important report on hypoxemic/reperfusion injury, concluded that hypoxemia increases vulnerability to reoxygenation damage. However, in our study, preischemic LV function of cyanotic rats was not impaired and there was no difference in change of cardiac output until 60 minutes in the working mode without ischemia between the cyanotic and control groups. Our findings suggest that cyanosis increases ischemic and reperfusion injury in addition to reoxygenation injury as described by Buckberg's group.

It has been recently noted that recovery of structure and function on reoxygenation is correlated with the activities of myocardial antioxidant enzyme or the concentrations of antioxidants. ${ }^{3}$ In a previous clinical study, del Nido and coworkers ${ }^{17}$ reported that hydroxy conjugated dienes, a chemical signature of free radical injury, are detected during elective repair of tetralogy of Fallot. They have suggested that cyanotic myocardium might be more susceptible to oxygen-mediated free radical injury. 


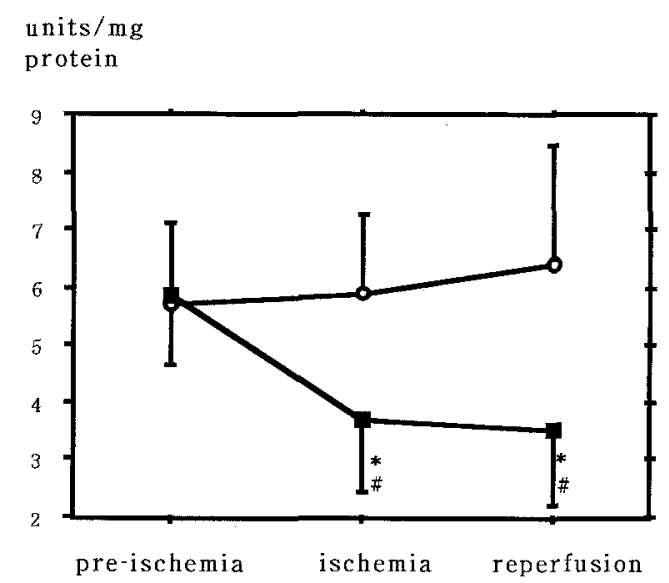

A mitochondrial-SOD

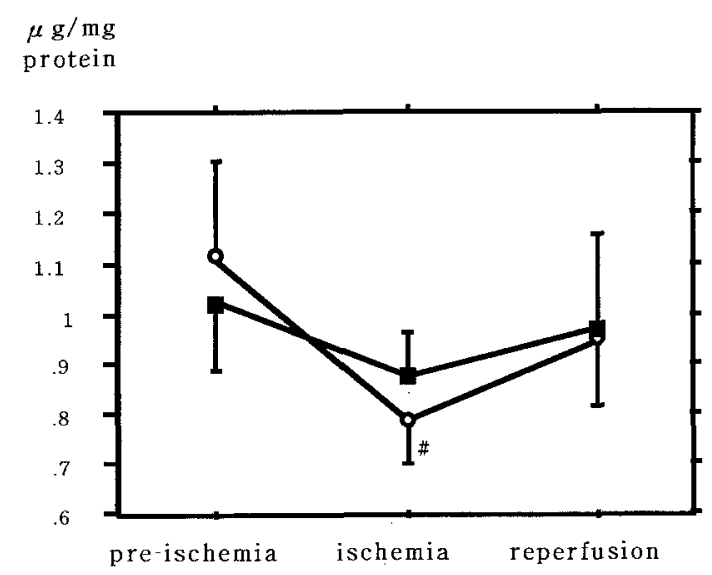

B
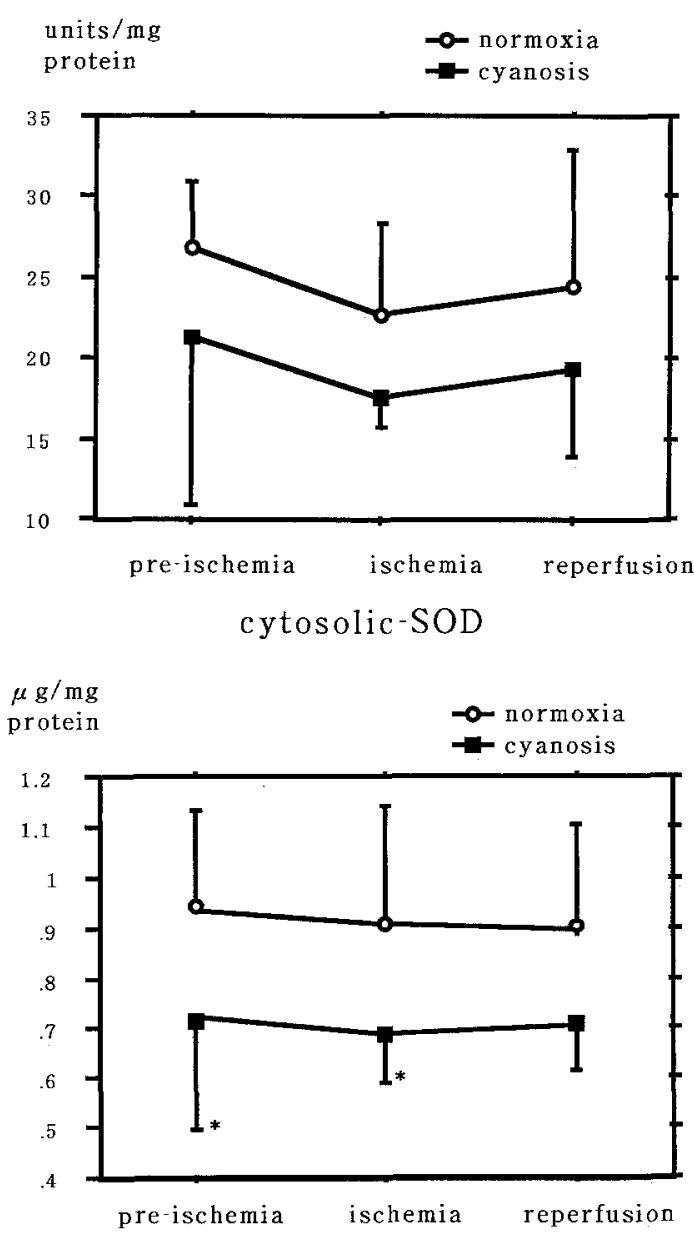

cytosolic-GSH

Fig. 3. Changes in myocardial antioxidant system. The content of GSH and the activities of myocardial SOD, GPX, and GR at the end of the preischemic, ischemic, and reperfusion periods. A, SOD. The activity of mitochondrial SOD was significantly reduced during ischemia in the cyanotic group. The activity of mitochondrial SOD at end-ischemia was significantly lower in the cyanotic group than in the control group. B, GSH. The vertical bars represent the standard deviations of the means. ${ }^{*} p<0.05$ when compared with matched control. \#p<0.05 when compared with preischemic data within the same group. GSH, Reduced glutathione; $S O D$, superoxide dismutase.

We therefore evaluated changes in myocardial antioxidants during chronic hypoxia, ischemia, and reperfusion.

Although many previous studies have demonstrated that acute hypoxia depresses myocardial antioxidants, ${ }^{3}$ few reports have evaluated changes in myocardial antioxidants during chronic hypoxia. ${ }^{4}$ To our knowledge, we are the first to evaluate changes in myocardial GSH and GR during chronic hypoxia. After chronic hypoxia, cytosolic GSH and cytosolic GR decreased. GSH is regenerated from oxidized glutathione by enzyme GR. Decrease in GR activity may be one of the causes of decrease in myocardial GSH during chronic hypoxia. Li and associates ${ }^{18}$ have reported that GPX activity in tetralogy of Fallot myocytes cultured with chronic hypoxia is significantly lower than with normoxia. In contrast to their result, we found that the activity of cytosolic GPX was higher in cyanotic myocardium than in noncyanotic myocardium. Kirshenbaum and Singal $^{19}$ have reported that hypertrophied hearts showed increased GPX. In our study, chronically hypoxic hearts showed hypertrophied right ventricles, which might have caused increase in cytosolic 


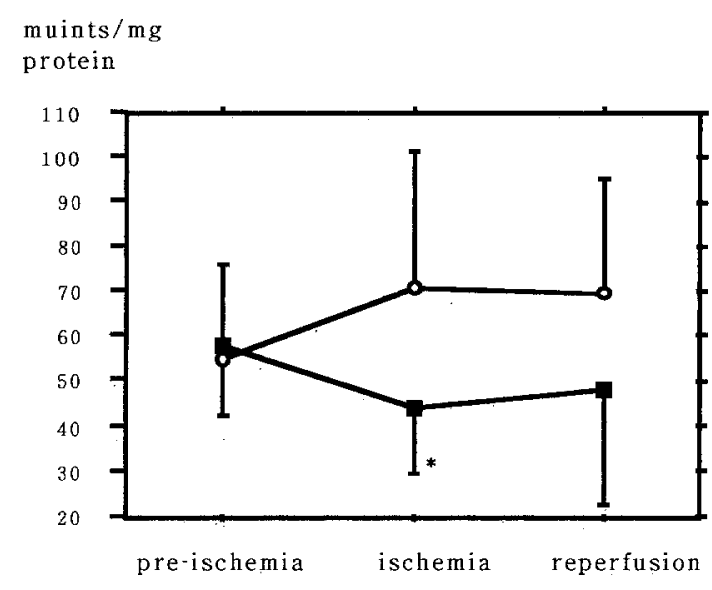

C

muints $/ \mathrm{mg}$

protein

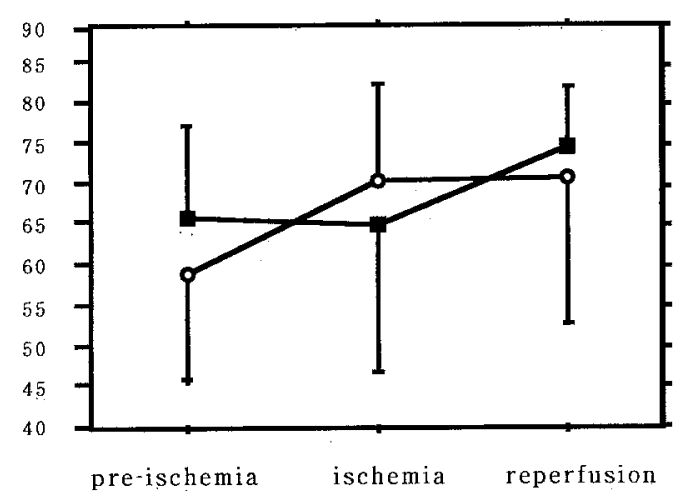

D
mitochondrial-GR

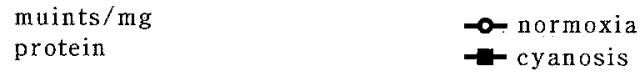

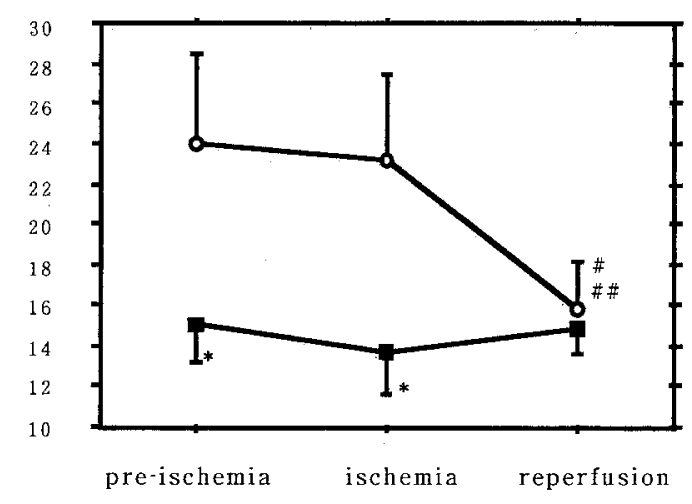

cytosolic-GR

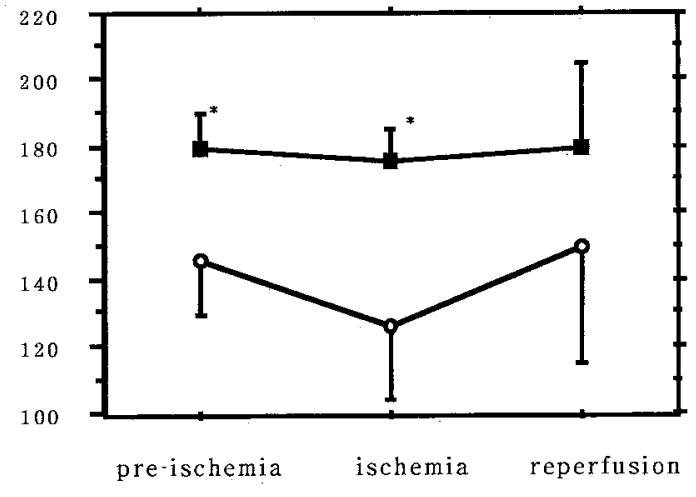

cytosolic-GPX

Fig. 3. Cont'd. C, GR. The myocardial content of cytosolic GSH and the activity of cytosolic GR were significantly lower in the cyanotic group at preischemia and end-ischemia than in the control group. D, GPX. The vertical bars represent the standard deviations of the means. ${ }^{*} p<0.05$ when compared with matched control. \#p $<0.05$ when compared with preischemic data within the same group. \#\#p $<0.05$ when compared with ischemic data within the same group. $G P X$, Glutathione peroxidase; $G R$, glutathione reductase.

GPX in the cyanotic myocardium. The activity of myocardial SOD was unchanged after chronic hypoxia. This result is consistent with a previous report in mice exposed to hypobaric chronic hypoxia for 6 to 8 weeks. ${ }^{4}$

Mitochondria are known to be one source of free radical release after ischemia. ${ }^{20}$ Galinanes and colleagues ${ }^{21}$ have demonstrated that pretreatment with PEG-SOD (polyethylene glycol, covalently linked to superoxide dismutase) before global ischemia prevents decrease in mitochondrial SOD and enhances postischemic recovery of LV function. The lower activity of mitochondrial SOD in cyanotic myocar- dium during ischemia may be one of the causes of impaired postischemic cardiac function in cyanotic hearts.

Glutathione itself acts as a free radical scavenger ${ }^{22}$ and acts as a substrate for GPX. Barasacchi and coworkers $^{23}$ have shown that glutathione-depleted hearts exhibit evidence of increased lipid peroxidation during oxygenated perfusion. Blaustein and associates ${ }^{24}$ have shown that in glutathione-depleted hearts (without altered levels of GPX), recovery of systolic function after ischemia is impaired, but it is improved when reperfusate is supplemented with glutathione. Pretreatment with precursors of glutathione biosyn- 
thesis increases cardiac glutathione and improves systolic after reperfusion performance. ${ }^{25}$ These studies demonstrate that endogenous glutathione is important for protection of myocardium from reperfusion injury. We believe that the lower content of cytosolic GSH in cyanotic myocardium during ischemia is another cause of impaired postischemic cardiac function. Furthermore, cytosolic GR was significantly lower in cyanotic rats during ischemia. Finally, because GR regenerates GSH from oxidized glutathione, the lower activity of GR in cyanotic myocardium during ischemia may also contribute to impaired postischemic cardiac function.

Further studies are required to measure parameters of reperfusion injury resulting from free radicals or to directly detect free radical generation during reperfusion with the use of electron resonance spectroscopy or spin trapping. Furthermore, studies to establish the methods that decrease reperfusion injury to cyanotic myocardium (for example, administration of free radical scavengers, blood-based reperfusate) are needed.

Current studies have shown that the mechanisms of myocardial stunning are the alteration of $\mathrm{Ca}^{2+}$ transport by the sarcoplasmic reticulum and a decrease in the $\mathrm{Ca}^{2+}$ sensitivity of the contractile proteins. ${ }^{26}$ Although oxygen-derived free radicals have been shown to be a cause of some of the elevation in intracellular $\mathrm{Ca}^{2+}$ caused by abnormal $\mathrm{Ca}^{2+}$ handling by the sarcoplasmic reticulum, ${ }^{27}$ we need to study whether chronic cyanosis may alter other key enzymes (for example, sarcoplasmic reticular calcium-adenosinetriphosphatase activity) ${ }^{28}$

The model used in our study has several limitations. First, we used an isolated perfused preparation. The preparation is denervated. ${ }^{29}$ However, there is an advantage that direct cardiovascular responses independent of various factors can be studied. Second, we used crystalloid solution in the perfusion circuit. Blood perfusion may have induced different results from those of crystalloid perfusion, ${ }^{30}$ However, we used simple crystalloid perfusate in the first step, because each blood component serves different roles during ischemia and reperfusion and may confuse our results.

In conclusion, this model of chronic hypoxia is useful to evaluate the effects of ischemia and reperfusion on cyanotic myocardium. Cyanosis impairs postischemic functional recovery. Cyanosis depresses myocardial antioxidant reserve, and ischemia further depresses antioxidant reserves in cyanotic myocardium, compared with noncyanotic myocardium. Our results suggest that reduced anti- oxidant reserve during ischemia in cyanotic myocardium may contribute to impaired postischemic functional recovery.

We gratefully acknowledge the technical assistance of Tetsuo Kawakami.

\section{REFERENCES}

1. Kirklin JW, Barratt-Boyes BG. Ventricular septal defect and pulmonary stenosis or atresia. In: Kirklin JW, Barratt-Boyes BG, editors. Cardiac surgery, 2nd ed. New York: Churchill Livingstone; 1993. p. 861-1012.

2. Lupinetti FM, Wareing TH, Huddleston CB, Collins JC, Boucek RJ Jr, Bender HW Jr, et al. Pathophysiology of chronic cyanosis in a canine model: functional and metabolic response to global ischemia. J Thorac Cardiovasc Surg 1985;90:291-6.

3. Dhaliwal H, Kirshenbaum LA, Randhawa AK, Singal PK. Correlation between antioxidant changes during hypoxia and recovery on reoxygenation. Am J Physiol 1991;261:H632-8.

4. Liu J, Simon LM, Phillips JR, Robin ED. Superoxide dismutase (SOD) activity in hypoxic mammalian systems. J Appl Physiol 1977;42:107-10.

5. Cryer A, Bartley W. The design and use of a hypoxic chamber for small animals. Lab Pract 1974;23:713-5.

6. Hearse DJ, Stewart DA, Braimbridge MV. Hypothermic arrest and potassium arrest: metabolic and myocardial protection during elective cardiac arrest. Circ Res 1975; 36:481-9.

7. Mitsuta K, Mizuta Y, Kohno M, Hiramatsu M, Mori A. The application of ESR spin trapping technique to the evaluation of SOD-like activity of biological substances. Bull Chem Soc Jpn 1990;63:187-91.

8. Sugiyama S; Hayakawa M, Kato T, Hanaki Y, Shimizu K, Ozawa T. Adverse effects of anti-tumor drug, cisplatin, on rat kidney mitochondria: disturbances in glutathione peroxidase activity. Biochem Biophys Res Commum 1989;159:1121-7.

9. Carlberg I, Mannervik B. Glutathione reductase. In: Meister A, editor. In methods in enzymology: glutamate, glutamine, glutathione, and related compounds. vol 113. New York: Academic Press; 1985. p. 484-90.

10. Hissin PJ, Hilf R. A fluorometric method for determination of oxidized and reduced glutathione in tissues. Anal Biochem 1976;74:214-26.

11. Ambrosio G, Flaherty JT, Duilio C, Tritto I, Santoro G, Elia PP, et al. Oxygen radicals generated at reflow include peroxidation of membrane lipids in reperfused hearts. J Clin Invest 1991;87:2056-66.

12. Del NP, Mickle DA, Wilson GJ, Benson LN, Weisel RD, Coles JG, et al. Inadequate myocardial protection with cold cardioplegic arrest during repair of tetralogy of Fallot. J Thorac Cardiovasc Surg 1988;95:223-9.

13. Ladoux A, Frelin C. Hypoxia is a strong inducer of vascular endothelial growth factor mRNA expression in the heart. Biochem Biophys Res Commun 1993;195:1005-10.

14. McGrath JJ, Bullard RW. Altered myocardial performance in response to anoxia after high-altitude exposure. J Appl Physiol 1968;25:761-4.

15. Anderson PG, Allard MF, Thomas GD, Bishop SP, Digerness $\mathrm{SB}$. Increased ischemic injury but decreased hypoxic injury in hypertrophied rat hearts. Circ Res 1990;67:948-59. 
16. Ihnken K, Morita K, Buckberg GD, Matheis G, Sherman MP, Allen BS, et al. Studies of hypoxemic/reoxygenation injury: without aortic clamping. II. Evidence for reoxygenation damage. J Thorac Cardiovasc Surg 1995;110:1171-81.

17. Del NP, Mickle D, Wilson GJ, Benson LN, Coles JG, Trusler GA, et al. Evidence of myocardial free radical injury during elective repair of tetralogy of Fallot. Circulation 1987;76:174-9.

18. Li RK, Mickle DA, Weisel RD, Tumiati LC, Jackowski G, Wu TW, et al. Effect of oxygen tension on the antioxidant enzyme activities of tetralogy of Fallot ventricular myocytes. J Mol Cell Cardiol 1989;21:567-75.

19. Kirshenbaum LA, Singal PK. Increase in endogenous antioxidant enzymes protects hearts against reperfusion injury, Am J Physiol 1993;265:H484-93.

20. Otani $H$, Tanaka $H$, Inoue $T$, et al. In vitro study on contribution of oxidative metabolism of isolated rabbit heart mitochondria to myocardial reperfusion injury. Circ Res 1984;55:168-75.

21. Galinanes M, Qiu Y, Ezrin A, Hearse DJ. PEG-SOD and myocardial protection: studies in the blood- and crystalloidperfused rabbit and rat hearts. Circulation 1992;86:672-82.

22. Tribble DL, Aw TY, Jones DP. The pathophysiological significance of lipid peroxidation in oxidative cell injury. Hepatology 1987;7:377-86.

23. Barasacchi R, Pelosi G, Camici P, Bonaldo L, Majorino M, Ursini F. Glutathione depletion increases chemilumines- cence emission and lipid peroxidation in the heart. Biochim Biophys Acta 1984;804:356-60.

24. Blaustein A, Deneke SM, Stolz RI, Baxter D, Healey N, Fanburg BL. Myocardial glutathione depletion impairs recovery after short periods of ischemia. Circulation 1989;80:1449-57.

25. Ceconi C, Curello S, Cargnoni A, Ferrari R, Albertini A, Visioli $\mathrm{O}$. The role of glutathione status in the protection against ischaemic and reperfusion damage: effects of $N$-acetyl cysteine. J Mol Cell Cardiol 1988;20:5-13.

26. Krause SM, Rozanski D. Effects of an increase in intracellular free $\left[\mathrm{Mg}^{2+}\right]$ after myocardial stunning on sarcoplasmic reticulum $\mathrm{Ca}^{2+}$ transport. Circulation 1991;84:1378-83.

27. Jabr RI, Cole WC. Alterations in electrical activity and membrane currents induced by intracellular oxygen-derived free radical stress in guinea pig ventricular myocytes. Circ Res 1993;72:1229-44.

28. Quantz M, Tchervenkov C, Chiu RC. Unique responses of immature hearts to ischemia: functional recovery versus initiation of contracture. J Thorac Cardiovasc Surg 1992;103:927-35.

29. Buckberg GD. Studies of hypoxemic/reoxygenation injury. I. Linkage between cardiac function and oxidant damage. J Thorac Cardiovase Surg 1995;110:1164-70.

30. Walters HL III, Digerness SB, Naftel DC, Waggoner JR III, Blackstone EH, Kirklin JW. The response to ischemia in blood perfused vs. crystalloid perfused isolated rat heart preparations. J Mol Cell Cardiol 1992;24:1063-77. 